\title{
Assessment of Knowledge, Perception and Readiness of Nigerians to Participate in the COVID-19 Vaccine Trial
}

\author{
Seyi Samson Enitan ${ }^{1 *}$, Adesola Oyekunle Oyekale ${ }^{2}$, Richard Yomi Akele ${ }^{3}$, Kayode Abraham Olawuyi ${ }^{4}$, Elisha Oluwatobi Olabisi ${ }^{5}$, \\ Amarachi Joy Nwankiti ${ }^{6}$, Esther Ngozi Adejumo ${ }^{1}$, and Comfort Bosede Enitan ${ }^{7}$
}

\author{
${ }^{1}$ Department of Medical Laboratory Science, Babcock University, Ilishan-Remo, Nigeria \\ ${ }^{2}$ Department of Chemical Pathology, Ladoke Akintola University of Technology, Oshogbo, Nigeria \\ ${ }^{3}$ Department of Medical Laboratory Science, Afe Babalola, Ado-Ekiti, Nigeria \\ Vom, Nigeria \\ ${ }^{5}$ Department of Nursing, Ladoke Akintola University of Technology, Oshogbo, Nigeria \\ ${ }^{6}$ Department of Histopathology, Federal College of Veterinary and Medical Laboratory Technology, Vom, Nigeria \\ ${ }^{7}$ Department of Pathology, Igbinedion University Teaching Hospital, Okada, Nigeria
}

${ }^{4}$ Department of Regional Support Laboratory for Animal Influenza and other Transboundary Animal Diseases, National Veterinary Research Institute,

*Corresponding author: Seyi Samson Enitan, Department of Medical Laboratory Science, Babcock University, Ilishan-Remo, Nigeria, Tel: +2348065483761; E-mail: enitans@babcock.edu.ng

Received: 12 Jun, 2020 | Accepted: 06 Jul, 2020 | Published: 12 Jul, 2020

Citation: Enitan SS, Oyekale AO, Akele RY, Olawuyi KA, Olabisi EO, et al. (2020) Assessment of Knowledge, Perception and Readiness of Nigerians to Participate in the COVID-19 Vaccine Trial. Int J Vaccine Immunizat 4(1): dx.doi.org/10.16966/2470-9948.123

Copyright: (C) 2020 Enitan SS, et al. This is an open-access article distributed under the terms of the Creative Commons Attribution License, which permits unrestricted use, distribution, and reproduction in any medium, provided the original author and source are credited.

\section{Abstract}

Background: Developing an effective and safe COVID-19 vaccine is a global public health necessity in containing the pandemic, however, recruiting volunteers can be challenging in a clinical trial phase because of poor knowledge, negative perception, ethical issues and safety concerns.

Aim: The survey was conducted to assess the knowledge, perception and readiness of Nigerians to participate in the COVID-19 vaccine trial.

Methods: This is a cross-sectional, web-based study conducted among the Nigerian populace from the $19^{\text {th }}$ May to the $22^{\text {nd }}$ of May, 2020. A $39-i t e m$ survey instrument (questionnaire), which required about 7 minutes to complete, was developed using google forms via the Survey Monkey Platform, validated and the internet link distributed randomly to consenting participants from the six geopolitical zones of the country via the social media. Descriptive statistics were carried out using Statistical Package for the Social Sciences Software-Version 25 (SPSS-25) to measure frequencies and percentages of the variables. Bivariate analysis was also conducted using chi-square and bivariate logistic regression, and statistical significance was determined by $p<0.05$ to identify predictors of Nigerians' readiness to participate in COVID-19 vaccine trials.

Results: A total of 465 responses were gathered from adult respondents (aged 18 years and above; median age: 34.5 years) from the six geopolitical zones of the Country: South-west (48.4\%), North-central (17.2\%), South-south (16.3\%), South-east (9.7\%), North-west (4.5\%) and North-east (3.9\%). A higher proportions of the respondents were Christians by religion ( $84.5 \%$ ) and were medical students (48.6\%), followed by medical professionals (20.2\%). Most of the participants used the social medial (80.2\%) as their source of COVID-19 information. 96.0\% of them had poor knowledge of the disease, while $39.0 \%$ had poor perception of the COVID-19 Vaccine trial. $22.6 \%$ were indifferent to the initiation of COVID-19 vaccine trial in Nigeria, $59.8 \%$ were in support, while $17.6 \%$ were not in support. A higher proportion of the respondents (80\%) were unwilling to participate in the COVID-19 vaccine trial, while $20 \%$ were willing. Age, gender, educational level, religion, occupation, nature of monthly income and geopolitical zone had no significant impact $(p>0.05)$ on the perception and readiness of the respondents to participate in the COVID-19 vaccines trial. However; religion significantly $\left(p=0.0001, \chi^{2}=20.797\right)$ influenced the knowledge of the disease among the respondents.

Conclusion: Misinformation and disinformation strengthen vaccine skepticism and could undermine efforts to end the coronavirus pandemic. The outcome of this study further underscores the need for adequate public health enlightenment on the role of vaccine in curbing the COVID-19 pandemic. This will ensure adequate deployment and acceptance of the vaccine when it finally arrives.

Keywords: COVID-19; Knowledge; Nigeria; Pandemic; Perception; Readiness; Trial; Vaccine

\section{Introduction}

The Coronavirus Disease-19 (COVID-19) outbreak that started in Wuhan, megacity of China in late December, 2019, has spread to 213 countries and territories, with more than 7.5 million total confirmed cases and 421,801 total deaths globally as at 12 June,
2020 and still counting [1]. Currently, no approved vaccines exist to prevent infection with the Severe Acute Respiratory Syndrome Coronavirus-2 (SARS-CoV-2), the causative agent of COVID-19 [2]. There are about 30 different strains isolated across the world just within 6 months of the outbreak [3]. Developing an effective and safe 
COVID-19 vaccine is a global public health necessity in containing the pandemic [4]. To this end, scientists are racing to identify and test possible vaccines for COVID-19 as nations struggle with the health, economic and societal consequences of the pandemic [5-7]. The head of the Global Alliance for Vaccines and Immunization (GAVI) has warned, "Nobody is safe unless everybody is safe," from the new coronavirus [8]. The global Target Product Profile (TPP) for vaccines against COVID-19 is focused on human vaccines designed for long term protection of persons at high ongoing risk of COVID-19 such as healthcare workers and for reactive use in outbreak settings with rapid onset of immunity [9]. Vaccines are especially needed by health care workers on the front lines and other vulnerable members of the population who have a higher risk of contracting the infection $[10,11]$. While vaccination is the most effective medical intervention ever recorded in human history; vaccine development and production is a financially demanding and herculean task requiring months to several years of pre-clinical and clinical trials before advancing to the licensure stage $[12,13]$. The WHO criteria for candidate vaccine evaluation and prioritization include: safety profile (25 points), potential for efficacy (25 points), vaccine stability (10 points), vaccine implementation (15 points) and vaccine availability (25 points) [14-17].

The continuous escalation of the virus underscores the need to accelerate the development of COVID-19 vaccines. Over 150 researchers consisting of virologists, vaccine scientists, product developers, manufacturers, regulators and funding agencies are all in a race to find a vaccine to stop the spread of the deadly virus, as nations of the world grapple with the economic and societal consequences of the virus lockdowns [18-21]. Countries around the world are using different vaccine technologies to try and find one that can halt the pandemic. There are more than 102 candidate vaccines that researchers are working on. More than seventy (70) of these are being tracked by the World Health Organization [21], nine (9) of which are now being tested. Some in the pre-clinical stage (e.g BNT162, INO-4800, Sanofi recombinant DNA vaccine etc.) and others such as mRNA-1273, Ad5-nCoV and ChAdOx1, are currently involved in clinical trials in humans $[11,13,16,22]$.

Two candidates are currently being tested in the United States. A Phase 1 clinical trial evaluating mRNA-1273 (a candidate vaccine developed by Moderna Inc.) has begun at Kaiser Permanente Washington Health Research Institute (KPWHRI) in Seattle. The trial is being funded by the National Institute of Allergy and Infectious Diseases (NIAID), part of the National Institutes of Health [23]. The second candidate, which is being developed by an American Biotech Firm (Inovio Pharmaceuticals) has begun in Philadelphia and Kansas City. The trial is being funded by the Bill \& Melinda Gates Foundation in collaboration with the Coalition for Epidemic Preparedness Innovations (CEPI). Trials for four other candidates are taking place in China under the umbrella of the Biotech Firm CanSino Biologics and the Medical Research Arm of the People's Liberation Army. The first human trial of a candidate vaccine (made from a weakened version of adenovirus from chimpanzees) developed by a team of researchers at Oxford University has begun in Europe involving 800 volunteers $[24,25]$. The Beijing and Wuhan Institutes of Biological Products, arms of state-run Sinopharm, are also carrying out trials on another two candidates, and trials for a vaccine developed by Biotech Firm Sinovac are also underway.

The trial will rapidly enroll and individually randomize very large numbers of adult participants in many different populations. Each participant will be contacted weekly for information as to whether any potentially relevant symptoms have arisen. Cases suggestive of
COVID-19 will be confirmed by laboratory testing using real-time reverse transcription-PCR (RT-PCR) assay (Gold standard). By using a shared placebo/control group and a common core protocol to evaluate multiple candidate vaccines in the trial, resources allocated to the evaluation of each candidate vaccine are judiciously saved, while a high standard scientific protocol is ensured. These trials are powered to provide sufficient evidence of vaccine safety and efficacy against COVID-19 to support decision-making about global vaccine deployment $[17,19,22]$. Together with global health actors and partners, the WHO has launched the access to COVID-19 tools ACT accelerator, a global collaboration to accelerate development for equitable access to new COVID-19 diagnostics, therapeutics and vaccines. Nothing less than 89 vaccines are being developed globally, including seven in clinical evaluation [26]. More than 100 countries have joined the solidarity trial and to date, over 1,200 patients have been randomized from the first five countries to evaluate the safety and efficacy of full drug and drug combinations [27]. By comparing the results from many separate studies that adhere to the same protocol, the WHO hopes to obtain strong evidence as a result of a large sample size [26].

Recruiting volunteers can be challenging in a clinical trial phase primarily because of ethical issues and safety concerns [12]. History shows that in the past most clinical trials were carried out in the developed countries mostly, but of recent there is a shift to the low and middle income countries. Nigeria with a total of 14,554 confirmed cases and 387 deaths as at June 11, 2020 [28], like her African counterparts (Zambia, Tunisia and Egypt) has indicated interest to participate in the WHO clinical COVID-19 vaccine trial [27]; even though the Government is committed to make fund available for Nigerian made vaccines [29]. To this end, the Federal government has enrolled some states (Lagos, Ogun, Kano, Kaduna and Sokoto), as well as the Federal Capital Territory (FCT) in the "Solidarity Trials" [26,30]. This move however has been met with some public criticism and opposition as obtainable elsewhere in the world. Nearly 1 in 5 Americans say they would not take a vaccine to prevent the disease [31]. This is partly because the COVID-19 era has generated a lot of fears, fake news and conspiracy theories that are likely to impact negatively on the success of recruitment of volunteers for the COVID-19 vaccine clinical trials [32].

Fears expressed by an average concerned Nigerian regarding the candidate vaccine trial include: fear of adverse effects/complications, disruption of daily routine, potential mutation, implantation of a microchip, racism, foreign attack, dominance and depopulation of the black race, as well as fear of death. It is shocking that till date; many do not believe that COVID-19 exists. Others are of the opinion that the pandemic was caused by installation of the $5 \mathrm{G}$ Network. Worst still, some think that COVID-19 is a myth, joke, political scam, fallout of economic war between world powers, a biological weapon, a laboratory escape or vaccine trial that went wrong. All these negative perceptions among the Nigerian populace will no doubt militate against the successful deployment and acceptance of the COVID-19 vaccine when it finally arrives. Generally, knowledge is thought to influence perception, [33] and perception in turn influences readiness to participate in any clinical trial [34]. Paucity of data on the knowledge, perception and readiness of Nigerians to participate in the COVID-19 vaccine trials necessitate this study. The aim of this study was therefore to assess the knowledge, perception and readiness of Nigerians to participate in the COVID-19 vaccine trial. To the best of our knowledge, this study is the first of its kind in Nigeria and we do hope data provided in this study will serve the benefit of the scientific community, particularly researchers who would undertake similar studies on a larger scale in the future. 


\section{Methods}

\section{Study design}

This was a rapid cross-sectional web-based survey conducted between $19^{\text {th }}$ and $22^{\text {nd }}$ of May, 2020, among adult Nigerians (aged 18 years and above) with access to the internet.

\section{Study area}

The study was conducted in the Federal Republic of Nigeria. Nigeria is located in West Africa on the Gulf of Guinea between Benin and Cameroon. It has an area of 923,768 square kilometers, including about 13,000 square kilometers of water. Currently, the country is divided into six (6) geopolitical zones: North-central, North-east, North-west, South-east, South-west and South-south (Figure 1), and has a population size of about 200 million with an annual population growth rate of 2.38 percent. Nigeria has more than 250 ethnic groups with three major tribes (Yoruba, Igbo and Hausa). Nigeria's population is split primarily between Islam (50 percent) and Christianity (40 percent), with the rest $10 \%$ into indigenous beliefs. Nigeria has proven oil reserves which serves as the major source of revenue. Urbanization and industrialization have led to a waste management crisis, resulting in widespread air, water, and soil pollution. There is a high rate of unemployment with the majority having a low standard of living. The country has a poor health care system and is one of the factors responsible for an average life expectancy of only 47 years [34]. Nigeria has had a past history of epidemics and pandemics including Yellow fever, Influenza, Lassa fever, Ebola, and is presently experiencing the COVID-19 outbreak [35].

\section{Study population}

The study population consists of consenting Nigerians from the six geopolitical zones of the country (North-east, North-west, Northcentral, South-west, South-east, and South-south).

\section{Inclusion criteria}

Only adult Nigerians (18 years and above) with access to the internet, irrespective of gender, cultural background and geopolitical zone were invited via social media platforms to participate in the survey.

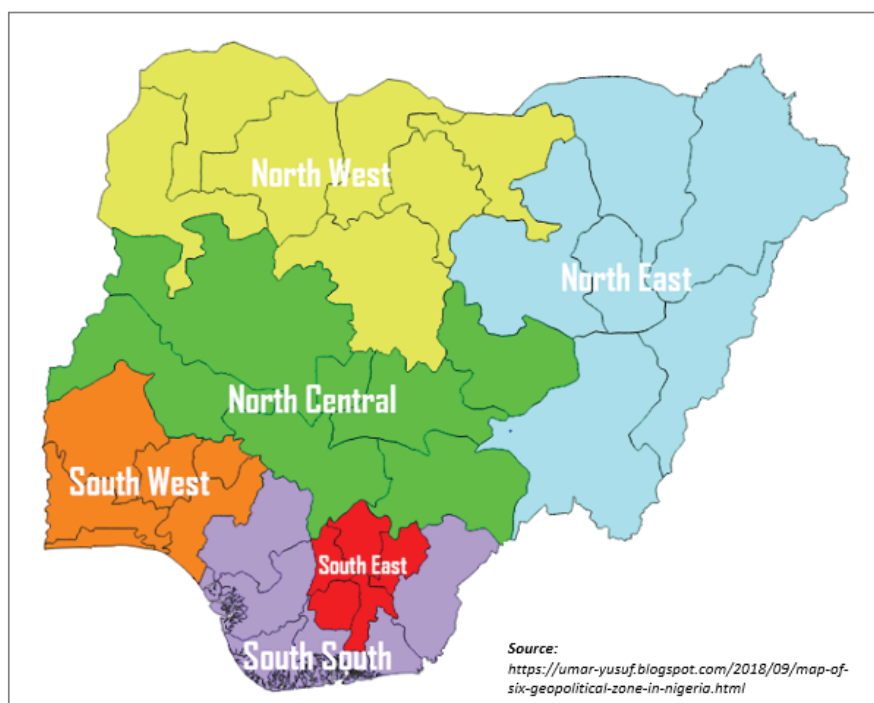

Figure 1: A map showing the six (6) geopolitical zones of the Federal Republic of Nigeria.

\section{Exclusion criteria}

Nigerians less than 18 years, irrespective of gender, cultural background and geopolitical zone were not invited to participate in the survey.

\section{Instrument for data collection}

A web-based validated, pretested and refined close ended selfdeveloped questionnaire created using Google forms hosted on the Survey Monkey Platform (https://www.surveymonkey.com/home/) was utilized to collect data from consenting study participants (18 years and above). The developed draft survey instrument was distributed to five randomly selected faculty members to assess its readability and validity before pretesting among 10 randomly selected social media users for clarity, relevance, and acceptability. Refinements were made as required to facilitate better comprehension and to organize the questions before the final survey was distributed to the study population. The survey instrument comprised 39 closedended questions and required about 7 minutes to complete. The 39item questionnaire was divided into 3 main parts. The first part was an introduction and included the title of the survey, names of the researchers, aim of the study and a check box for the participant to indicate their consent to participate in the study. The second part assessed the respondents' socio-demographic characteristics (12 items), while the remaining part assessed participants' knowledge, perception and readiness to participate in the COVID-19 vaccine trial: awareness of COVID-19 (2 items), source of information (1 item), risk of exposure (3 items), previous testing and treated for COVID-19 (2 items), signs and symptoms of COVID-19 (1 item), prevention and control (1 item), history of past vaccination (2 items), COVID-19 vaccine development $(11$ items) and readiness to participate in COVID-19 vaccine trial (4 items). The survey was self-paced, so the participants had sufficient time to read, comprehend, and answer all the questions.

\section{Method of Data Collection}

The questionnaire internet link (https://forms.gle/ Kg19Q8EcPYFLjCDf8) was shared on the $19^{\text {th }}$ of May, 2020 to consenting participants (18 years and above) from the six geopolitical zones of the country via various social media platforms (including WhatsApp, Facebook, etc.) requesting interested individuals to click on the web-link to complete the question items. On clicking the web-link, an introductory interface appeared first where the study participants read the title of the survey, aim of the study and consent to participate in the study. The research questions were stated in clear, simple, and unambiguous terms for easy comprehension and the research coordinators were available via the social media platforms to attend to any enquiry or provide more clarity. The data was automatically retrieved from the Google data base on $22^{\text {nd }}$ of May, 2020.

\section{Ethical Consideration}

Informed consent was obtained from the participants with assurance of anonymity and confidentiality prior to their participation in the survey. Respondents were given the right to refuse to take part in the survey. The participation in the survey was made voluntary, without any form of coercion and was not compensated. Anonymity and confidentiality were maintained throughout the study. All data were stored in a protected file with access to information limited only to the researchers in charge of the survey. The study was performed following the World Medical Association Declaration of Helsinki [36]. 


\section{Data Analyses}

Data were entered using Microsoft excel version 2016 and analyzed using Statistical Package for the Social Sciences software (SPSS) version 25, Chicago, IL. Descriptive statistics were carried out to measure frequencies and percentages of the variables. The knowledge variables were recorded to binary level such that respondents with correct option in the knowledge variables were coded 1, while not having correct knowledge was coded 0. Good knowledge of participants on COVID-19 was determined by a knowledge score of $\geq 70 \%$ and lesser scores were considered to have poor knowledge. Readiness of Nigerians was grouped into "willing" and "not willing" based on their responses to the related questions. Beyond descriptive statistics, bivariate analysis was conducted using chi-square and bivariate logistic regression and statistical significance was determined by $\mathrm{P}<0.05$ [37] to identify predictors of readiness of Nigerians to participate in COVID-19 vaccine trials. Significant variables in the bivariate analysis were included in the multivariate logistic regression model. Statistical analysis outputs were presented using tables and charts.

\section{Results}

A total of 465 adult respondents (aged 18 years and above; median age: 34.5 years) from the six geopolitical zones of the Country participated in the quick web-based survey. The Southwest geopolitical zone had the highest participants (48.4\%), while the Northeast geopolitical zone had the lowest (3.9\%) (Figure 2). A higher proportion of them were urban dwellers $(72.5 \%)$, followed by sub-urban dwellers $(21.3 \%)$ and lastly rural dwellers (6.2\%) (Figure 3). Also, a higher proportion of the respondents were within the age range of $18-25$ years $(63.9 \%)$ and were females (61.7\%). Three hundred and ninety-three, 393 (84.5\%) representing a higher proportion of the respondents were Christians by religion. All the respondents (100\%) had a tertiary level of formal education, with $226(48.6 \%)$ and $94(20.2 \%)$ being medical students and medical professionals respectively. Farmers, the clergy and retirees were the least represented (3 [0.6\%] each). A high proportion of the respondents (21.0\%) had no monthly source of income, though greater cluster earned between \#18,000-\#50,000 (24.5\%) and >\#100,000 monthly (21.5\%) (Table 1).

Respondents' Knowledge of COVID-19 is presented in table 2. The majority of the respondents $(96.3 \%)$ had a prior knowledge of COVID-19. Twenty-five of them (5.4\%) knew at least one family

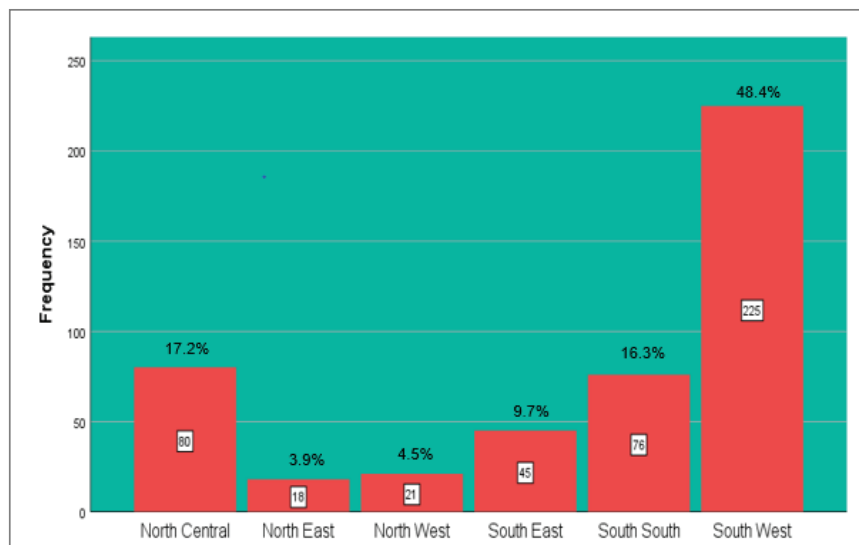

Figure 2: A bar chart showing the distribution of the respondents based on geopolitical zones.

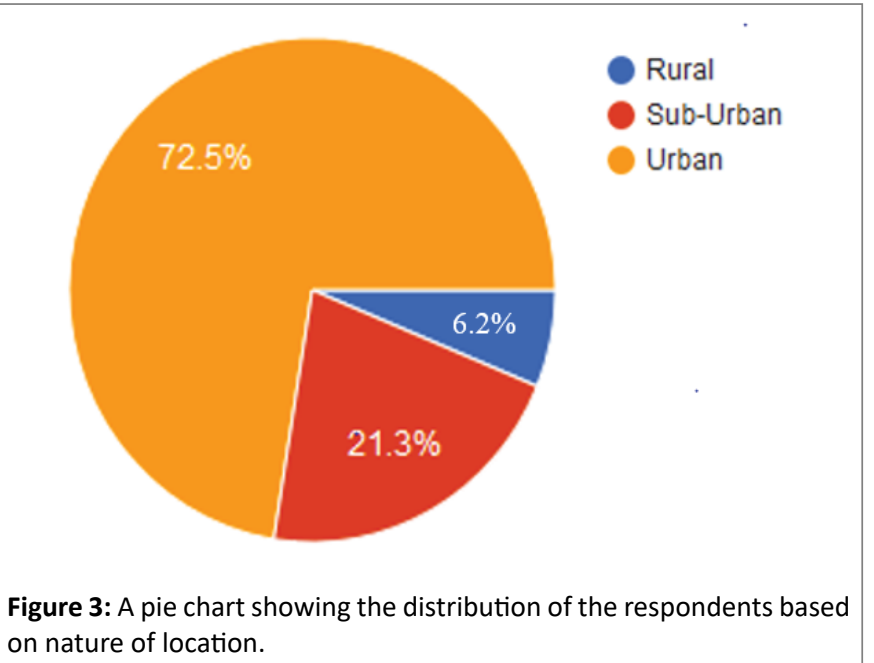

on nature of location.

Table 1: Socio-demographic characteristics of the respondents.

\begin{tabular}{|c|c|c|c|}
\hline Characteristics & Category & $\begin{array}{l}\text { Frequency } \\
\text { (N) }\end{array}$ & $\begin{array}{l}\text { Percentage } \\
\text { (\%) }\end{array}$ \\
\hline \multirow{3}{*}{ Gender } & Female & 287 & 61.7 \\
\hline & Male & 173 & 37.2 \\
\hline & Prefer not to say & 5 & 1.1 \\
\hline \multirow{5}{*}{ Age group } & $18-25 y r s$ & 297 & 63.9 \\
\hline & $26-33 y r s$ & 57 & 12.3 \\
\hline & $34-41 y r s$ & 61 & 13.1 \\
\hline & $42-49$ & 34 & 7.3 \\
\hline & Above 50yrs & 16 & 3.4 \\
\hline \multirow{4}{*}{ Religion } & Christianity & 393 & 84.5 \\
\hline & Islam & 68 & 14.6 \\
\hline & Others & 3 & 0.6 \\
\hline & Traditional & 1 & 0.2 \\
\hline Educational level & Tertiary & 465 & 100.0 \\
\hline \multirow{11}{*}{ Occupation } & Artisan & 4 & 0.9 \\
\hline & Civil Servant & 50 & 10.8 \\
\hline & Clergy & 3 & 0.6 \\
\hline & Farmer & 3 & 00.6 \\
\hline & Medical Professional & 94 & 20.2 \\
\hline & Medical student & 226 & 48.6 \\
\hline & Non-Medical Professional & 19 & 4.1 \\
\hline & Non-Medical student & 36 & 7.7 \\
\hline & Retiree & 3 & 0.6 \\
\hline & Trader & 11 & 2.4 \\
\hline & Unemployed & 16 & 3.4 \\
\hline \multirow{5}{*}{ Monthly income } & None & 98 & 21.0 \\
\hline & $\leq \mathrm{N} 18,000$ & 88 & 18.9 \\
\hline & N 18,000-N 50,000 & 114 & 24.5 \\
\hline & N 50,000-N 100,000 & 65 & 14.0 \\
\hline & $\geq N 100,000$ & 100 & 21.5 \\
\hline
\end{tabular}


Table 2: Respondents' knowledge of COVID-19.

\begin{tabular}{|c|c|c|c|}
\hline Question & Response & $\begin{array}{l}\text { Frequency } \\
\text { (N) }\end{array}$ & $\begin{array}{c}\text { Percentage } \\
(\%)\end{array}$ \\
\hline \multirow{3}{*}{$\begin{array}{l}\text { Have you heard of COVID-19 } \\
\text { before? }\end{array}$} & Maybe & 2 & 0.4 \\
\hline & No & 15 & 3.2 \\
\hline & Yes & 448 & 96.3 \\
\hline \multirow{2}{*}{$\begin{array}{l}\text { Do you know of any family } \\
\text { member who has been } \\
\text { tested and treated for } \\
\text { COVID-19? }\end{array}$} & NO & 440 & 94.6 \\
\hline & Yes & 25 & 5.4 \\
\hline \multirow{3}{*}{$\begin{array}{l}\text { Does the nature of your job } \\
\text { or life style put you at risk of } \\
\text { COVID-19 }\end{array}$} & Maybe & 67 & 14.4 \\
\hline & No & 181 & 38.9 \\
\hline & Yes & 217 & 46.7 \\
\hline \multirow{3}{*}{$\begin{array}{l}\text { Do you consider yourself } \\
\text { susceptible to COVID-19? }\end{array}$} & Maybe & 115 & 24.7 \\
\hline & No & 167 & 35.9 \\
\hline & Yes & 183 & 39.4 \\
\hline \multirow{6}{*}{$\begin{array}{l}\text { If yes, how do you rate your } \\
\text { potential risk of exposure to } \\
\text { COVID-19? }\end{array}$} & None & 98 & 21.1 \\
\hline & Very low & 77 & 16.6 \\
\hline & Low & 96 & 20.6 \\
\hline & Intermediate & 100 & 21.5 \\
\hline & High & 63 & 13.5 \\
\hline & Very high & 31 & 6.7 \\
\hline
\end{tabular}

member who had been tested and treated for COVID-19. 46.7\% $(217 / 465)$ confirmed that the nature of their job or life style predisposes them to COVID-19 infection. 183 (39.4) considered themselves susceptible to COVID-19.

Respondents' medium of awareness of COVID-19 is presented in figure 4. Most of them had the social media (80.2\%) and internet (76.3\%) as their major source of COVID-19 information. Also, the respondent's knowledge of signs and symptoms associated with COVID-19 is presented in figure 5. 444 (95.5\%), 430 (92.5\%), $423(91.0 \%)$ and $293(63.0 \%)$ indicated difficulty in breathing, dry cough, fever and chest pain as signs and symptoms associated with COVID-19, respectively, amongst others.

Respondents' knowledge of SARS-CoV-2 is presented in Figure 6. Most of them believed that the virus is real (88.6\%), highly infectious and deadly (63.4\%), with no standard cure or vaccine (53.1\%). While others opined that the virus is myths $(1.1 \%)$, affected only the rich $(0.9 \%)$, affect only the elderly (1.9\%), caused by $5 \mathrm{G}$ network $(3.0 \%)$, vaccine trial went wrong (8.4\%) and a biological weapon $(37.2 \%)$ amongst other assumptions.

Respondents' knowledge of measures to curb the COVID-19 pandemic is presented in figure 7. Most of them indicated social distancing (94.4\%), followed by hand hygiene (92.9\%), isolation and quarantine $(86.0 \%)$, treatment of confirmed cases $(81.9 \%)$, respiratory hygiene $(61.7 \%)$ and mass vaccination $(43.9 \%)$ among others. The rating of respondents' knowledge of COVID-19 is presented in figure 8. A higher proportion of them $(96.0 \%)$ had poor knowledge of the disease. While only a few (4.0\%) had good knowledge of the disease. Age, gender, occupation, nature of monthly income and geopolitical zone of respondents did not impact significantly on the knowledge of the disease among the respondents ( $p>0.05)$, however; religion $\left(p=0.0001, \chi^{2}=20.797,95 \% \mathrm{CI}=0.03-0.04\right)$ did with a larger proportion of those of the Islamic faith having a poor knowledge of the disease.

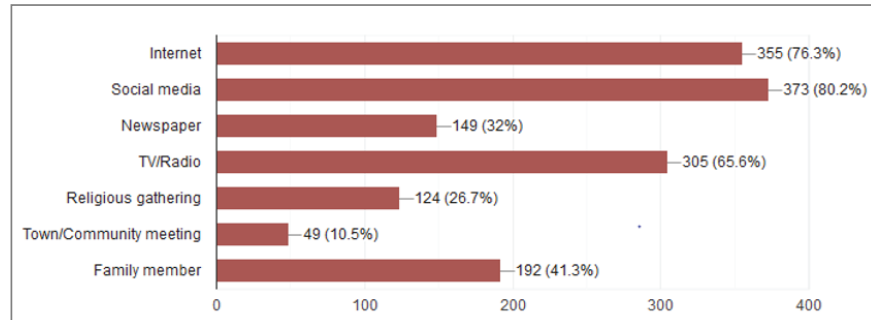

Figure 4: A horizontal bar chart showing respondent's medium of awareness of COVID-19.

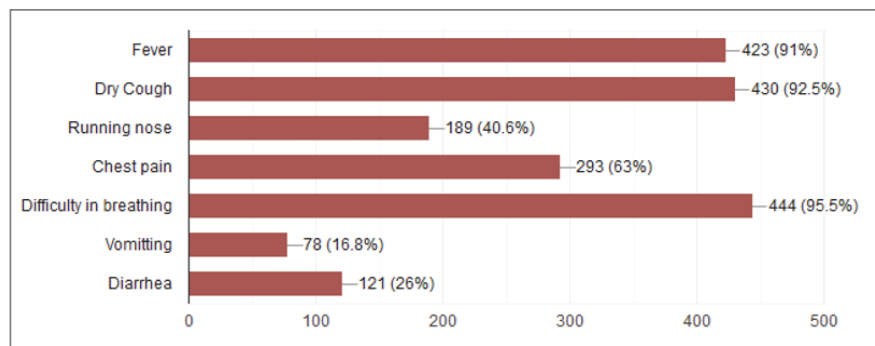

Figure 5: A horizontal bar chart showing respondent's knowledge of signs and symptoms associated with COVID-19.

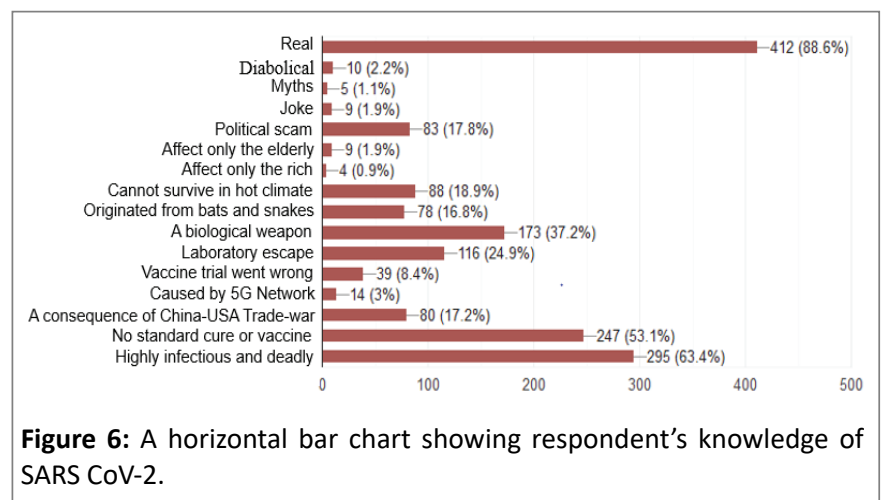

Furthermore, respondents' perception of COVID-19 vaccine trial is presented in table 3. A large part of the respondents saw the need to develop a vaccine to aid in the struggle against the pandemic $(75.3 \%)$, many of whom $(76.8 \%)$ were aware that several COVID-19 vaccine candidates are being developed and 55.5\% were aware that Nigeria had indicated interest to participate in the WHO COVID-19 trial. 17.6\% were against the COVID-19 vaccine trial, $15.3 \%$ were in support and willing to participate if given a chance, while only $6.2 \%$ of the respondents indicated interest in participating in the vaccine trial even if it will affect their daily life activity. $9.7 \%$ and $52.3 \%$ of them opined that vaccine trials should be initiated in residential homes and isolation centres, respectively. $39.8 \%$ $(185 / 465)$ feared that the vaccine may not be affordable and accessible for the common man.

Various fears expressed by the respondents regarding the COVID-19 vaccine trial is presented in figure 9. Eighty percent (80\%) were afraid of adverse effects/complication that may be associated with the vaccine, $30.8 \%$ were afraid of the vaccine been used as a medium for implantation of microchips, $11.8 \%$ were afraid of disruption of daily routine, $26.9 \%$ fear that the vaccine may be used as a biological weapon, while $50.5 \%$ are afraid of vaccine related death. 


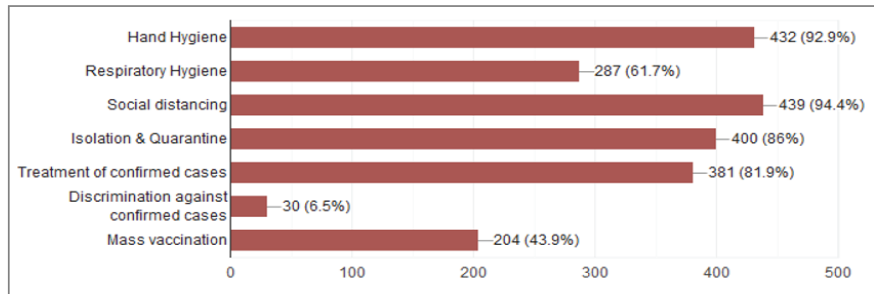

Figure 7: A horizontal bar chart showing respondents' knowledge of measures to curb the COVID-19 pandemic.

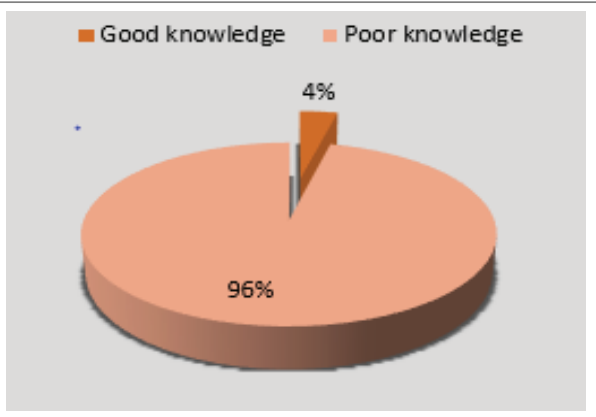

Figure 8: A pie chart showing rating of Respondents' knowledge of COVID-19.

Table 3: Respondents' perception of COVID-19 vaccine trial.

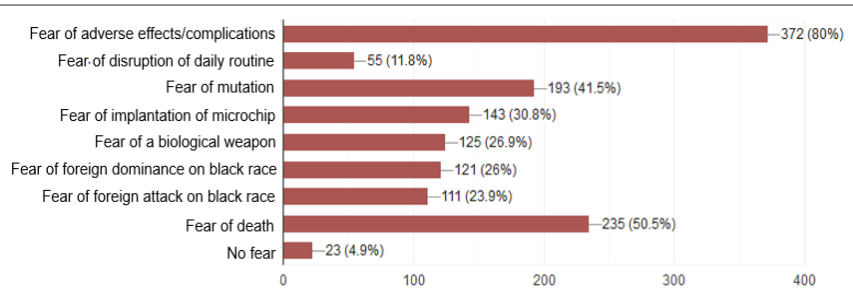

Figure 9: A horizontal bar chart showing respondents' fears regarding the COVID-19 vaccine trial.

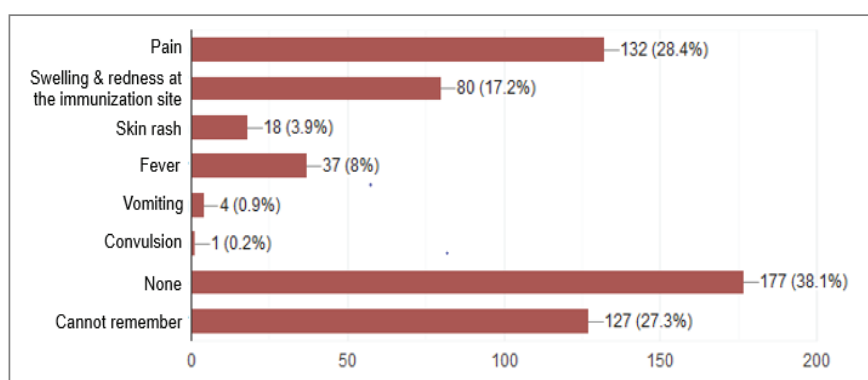

Figure 10: A horizontalbar chart showing respondents' history of side effects associated with past vaccination.

Do you think the development of a vaccine can help in the fight against the pandemic?

Are you aware that there are several candidate COVID-19 vaccines being developed?

Are you aware that Nigeria has indicated interest in the WHO COVID-19 vaccine trial?

What is your stand on the COVID-19 vaccine trial based on what you know?

Where do you think vaccine trial should take place?

If you know the COVID-19 vaccine trial can affect your daily life activity after the experiment, will you still make yourself available for it?

Do you think the COVID-19 vaccine will be affordable and accessible by the common man?

\begin{tabular}{|c|c|c|}
\hline Response & Frequency $(\mathrm{N})$ & Percentage (\%) \\
\hline Maybe & 90 & 19.4 \\
\hline No & 25 & 5.4 \\
\hline Yes & 350 & 75.3 \\
\hline Maybe & 41 & 8.8 \\
\hline No & 67 & 14.4 \\
\hline Yes & 357 & 76.8 \\
\hline Maybe & 25 & 5.4 \\
\hline No & 182 & 39.1 \\
\hline Yes & 258 & 55.5 \\
\hline I'm indifferent & 105 & 22.6 \\
\hline I'm in support & 278 & 59.8 \\
\hline I'm not in support & 82 & 17.6 \\
\hline Clinics & 89 & 19.1 \\
\hline Day cares & 1 & 0.2 \\
\hline Isolation centres & 243 & 52.3 \\
\hline Prisons & 23 & 4.9 \\
\hline Refugee camps & 7 & 1.5 \\
\hline Residential homes & 45 & 9.7 \\
\hline No idea & 57 & 12.3 \\
\hline Maybe & 56 & 12.0 \\
\hline No & 380 & 81.7 \\
\hline Yes & 29 & 6.2 \\
\hline Maybe & 180 & 38.7 \\
\hline No & 185 & 39.8 \\
\hline Yes & 100 & 21.5 \\
\hline
\end{tabular}


Respondents' history of side effects following past vaccination is presented in figure 10. They include: pain (28.4\%), swelling and redness at the immunization site $(17.2 \%)$, skin rash $(3.9 \%)$, fever $(8.0 \%)$, vomiting $(0.9 \%)$ and convulsion $(0.2 \%)$.

The rating of respondents' perception of COVID-19 vaccine trial is presented in figure 11. A higher proportion of them (61.0\%) had good perception of the vaccine trial, while the remaining $39.0 \%$ had poor perception of it. Age ( $\left.\mathrm{p}=0.557, \chi^{2}=3.004\right)$, occupation $(\mathrm{P}=0.367$, $\left.\chi^{2}=10.879\right)$, gender $\left(\mathrm{P}=0.999, \chi^{2}=0.001\right)$, religion $\left(\mathrm{P}=0.397, \chi^{2}=2.967\right)$, occupation $\left(\mathrm{P}=0.367, \chi^{2}=10.879\right)$, monthly income $(\mathrm{P}=0.073$, $\left.\chi^{2}=10.094\right)$ and geopolitical zone $\left(\mathrm{P}=0.948, \chi^{2}=1.164\right)$ had no significant influence on the perception of COVID-19 vaccines among the respondents.

Respondents' readiness to participate in the COVID-19 Vaccine Trial is presented in figure 12. Only a very small proportion of them (20\%) indicated that they were willing to participate in the COVID-19 vaccine trial if given a chance, while a higher proportion of them $(80 \%)$ indicated that they were not willing. Age $\left(\mathrm{p}=0.369, \chi^{2}=4.280\right)$, gender $\left(\mathrm{P}=0.990, \chi^{2}=0.021\right)$, religion $\left(\mathrm{P}=0.088, \chi^{2}=6.535\right)$, occupation $\left(\mathrm{P}=0.303, \chi^{2}=11.741\right)$, monthly income $\left(\mathrm{P}=0.154, \chi^{2}=8.037\right)$ and geopolitical zone $\left(\mathrm{P}=0.293, \chi^{2}=6.141\right)$ had no significant influence on the readiness of the respondents to participate in the COVID-19 vaccine trial.

Type of vaccines preferred by the respondent for the COVID-19 vaccine trial is presented in figure 13. A higher proportion of them preferred live attenuated vaccine $(27.7 \%)$, followed by inactivated vaccine $(24.3 \%)$, DNA vaccine $(11.4 \%)$ and Recombinant vaccine (9.2\%). 27.3\% of them indicated none. Routes of vaccine administration preferred by the respondents for the COVID-19 vaccine trial are presented in figure 14. A higher proportion of them preferred oral (36.6\%), followed by intramuscular $(31.4 \%)$ and subcutaneous (10.3\%). $21.7 \%$ of them indicated none.

Respondents' recommendations on the COVID-19 vaccine trial is presented in figure 15 and were as follows: be made optional (51.0\%), be made mandatory (22.2\%), be made available and accessible to all at no cost $(68.0 \%)$, be made available and accessible to all at a fair cost (23.0\%), be made available and accessible on the basis of religion, tribal and political affiliation (6.5\%), be made available and accessible to all, regardless of religion, tribal and political affiliation (52.9\%). Lastly, 66.5\% (309/465) of the respondents indicated that they have

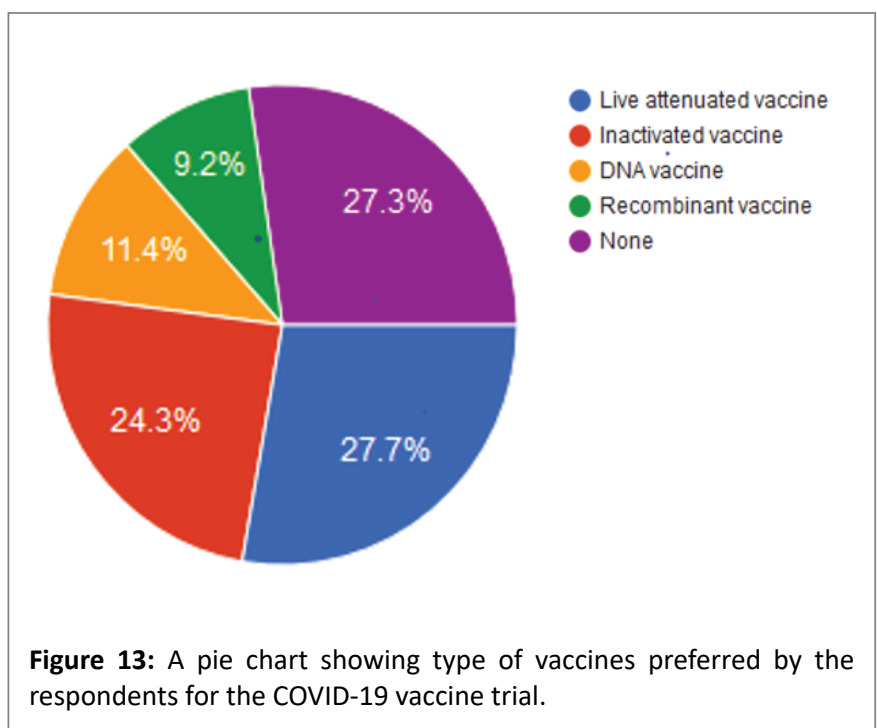

Figure 11: A pie chart showing rating of Respondents' perception of COVID-19 Vaccine Trial.
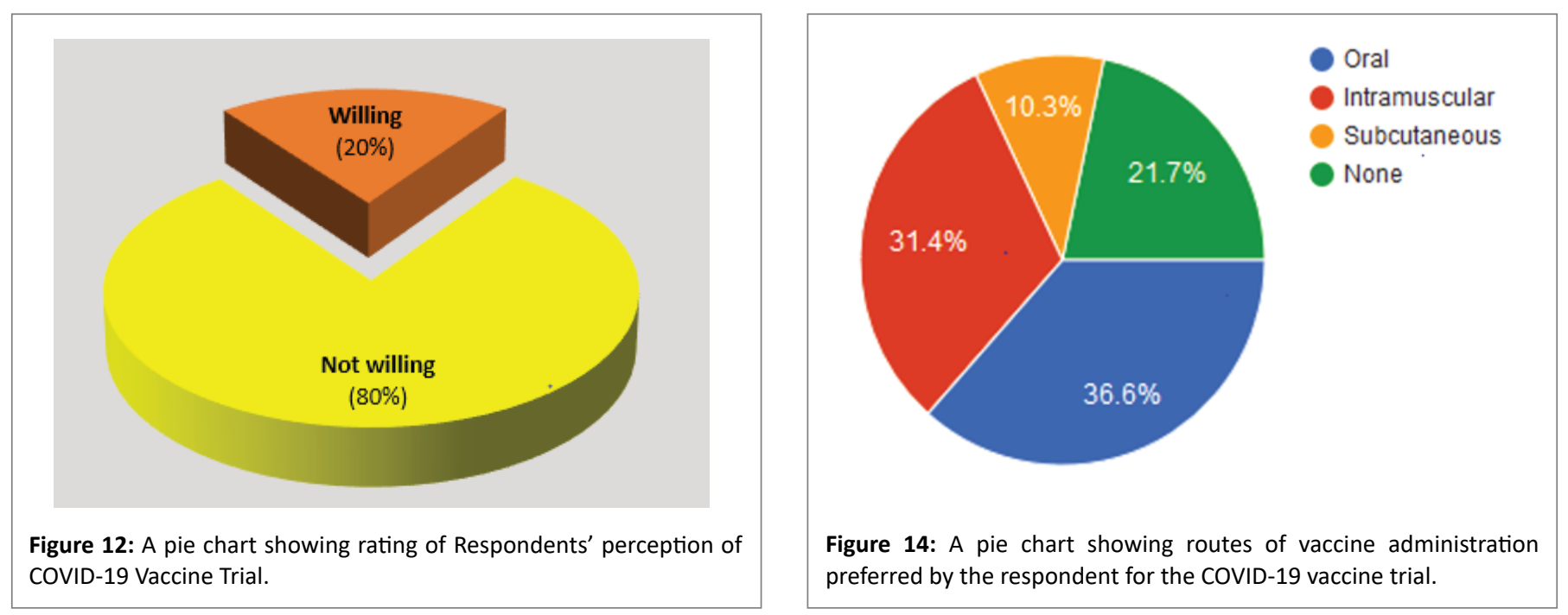

Figure 12: A pie chart showing rating of Respondents' perception of COVID-19 Vaccine Trial. preferred by the respondent for the COVID-19 vaccine trial. 
no confidence in the Nigeria Centre for Disease Control (NCDC) to coordinate and implement the COVID-19 vaccine trial successfully, while only $1.2 \%(6 / 465)$ were very confident (Figure 16$)$.

\section{Discussion}

Clinical trial is a crucial indicator and is pivotal in the development and licensure of novel vaccines for human use; however, recruitment of volunteers for the purpose of vaccine trials can be very challenging due to poor knowledge, negative perception, lack of confidence in the process, as well as adherence to conspiracy theories surrounding vaccine development and deployment $[33,34,38,39]$.

The outcome of this present study is partly similar to those of Olapegba PO, et al. [40] conducted among the Nigerian populace, with a higher proportion of the respondents from the South-west geopolitical zones of the country (68.5\%), age range (15-24 years) and mostly Christians by religion $(62.1 \%)$. On the other hand, the study differs from ours as higher proportion of their respondents were males $(58.0 \%)$ and had the mass media $(81.5 \%)$ as their main source of COVID-19 information.

Furthermore, our study differs from those of Akshaya SB, et al. [41]. While majority of our respondents were females, medical students, aged 18-25 years, they had more of male $(51.6 \%)$ and medical professional (30.2\%) respondents, aged $25-34$ years (32.1\%). $96 \%$ of our respondents had poor knowledge of the disease against the $61 \%$ they reported. However; the two studies share one thing in common, as majority of the respondents used the social media to obtain information on COVID-19, $80.2 \%$ and $61.0 \%$, respectively.

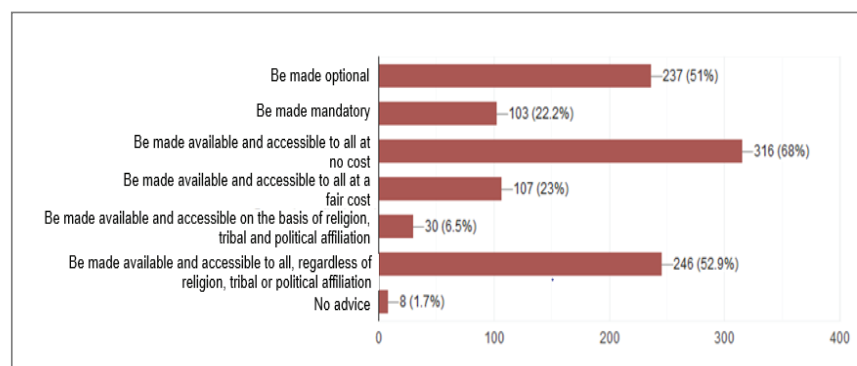

Figure 15: A horizontal bar chart showing recommendations of respondents on the COVID-19 vaccine trial.

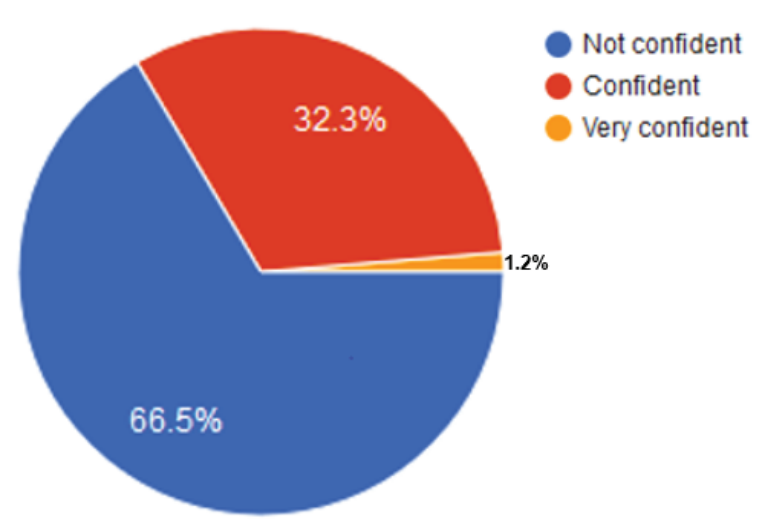

Figure 16: A pie chart showing respondents' confidence in the Nigeria Centre for Disease Control (NCDC) to coordinate and implement the COVID-19 vaccine trial successful.
The current study also vary from those of Taghriret $\mathrm{MH}$, et al. [42] conducted among 240 Iranian medical students. $79.6 \%$ of them had good knowledge of the disease, while $94.2 \%$ had high level of performance in preventive behaviors. Risk perception was significantly different between stagers and interns and between those being trained in emergency room (ER) and non-ER wards.

Still, our study partly agrees and disagrees with those of Saqlain $M$, et al. [43] conducted among 689 Pakistanis with a higher proportion of their respondents being males (62.6\%), less than 30 years (64.3\%), without source of income (76.8\%), have heard about disease $(93.9 \%)$, used social media as source of information on COVID-19 (66.6\%) and more than $80 \%$ of them correctly know that fever, cough, and shortness of breath are the symptoms of COVID-19. Unlike our findings, their study shows that respondents' knowledge of COVID-19 was significantly associated with higher educational status and monthly income $(\mathrm{OR}>1.00, \mathrm{p}<0.05)$. Positive practices were also significantly $(O R>1.00, p<0.05)$ related to the older age $(\geq 50$ years $)$, higher education, higher income and good knowledge regarding COVID-19. The variation in our study compared to other studies may be attributed to differences in the socio-demographic characteristics and geographical locations of the respondents.

Furthermore, $80.0 \%$ of the respondents in this current study indicated that they are unwilling to take the COVID-19 vaccine, while $20.0 \%$ indicated that they were willing, most of which were 18-25 years $(12.5 \%)$. This contradicts the latest data of a survey conducted by Morning Consult that shows that a higher proportion of Americans $(80 \%)$ are willing to take the vaccine. According to Perry D [44], the age group most likely to take the COVID-19 vaccine in America, were those between 35 and 44 years old. The outcome of the poll further revealed that $53 \%$ of Americans in this age group would get vaccinated, $18 \%$ would not, while $28 \%$ are uncertain. By a wide margin in the surveys conducted by Morning Consult, Republicans (20\%) are more likely than Democrats $(7 \%)$ to insist they would not get vaccinated against COVID-19. While sixteen percent (16\%) of political independents said they would not get vaccinated [44]. The reason for the disparity in the Americans-Nigerians responses is mostly like due to the nature and extent of public health enlightenment interventions on the role of vaccine in curbing the pandemic being executed in the United State of America compared to Nigeria.

More than half of our respondents were of the opinion that vaccine trials should take place in isolation centres. Vaccine trial in isolation centres will no doubt disrupt the daily life of the volunteers and that will in a way discourage people from participating as evident by the sharp decline in those willing to participate in trial (from $20 \%$ to $6.2 \%)$, if the vaccine trial will affect their daily life. The idea of having volunteers confined to isolation centre throughout the trial period is very erroneous, because vaccines are preventive interventions, not curative. They are designed to confirm immunity in healthy individuals with no established infection. Going by the design of any typical vaccine clinical trial, volunteers should be able to live their normal life uninterrupted after receiving the vaccine, though follow up visits are usually required to monitor how well they are doing [22,24].

Furthermore, while the COVID-19 vaccine is still months away, there have been growing concerns that the government might force vaccinations on unwilling citizens when the vaccine finally arrives. The fear that men in masks will start knocking on doors and forcing people to get vaccinated is part of the concerns of the anti-vaccine movement. The "No vaccine" advocates believe that vaccines are unwholesome tools for government control over the masses. To this end, they are therefore ready to resist mandatory vaccination by all means [45]. For 
now, the US polling suggests that a higher proportion of the public still supports vaccines, but anti-vaccine protesters are making more noise than ever. At rallies protesting against prolong lockdown in California in May, 2020 for instance; some protestors were seen carrying placards with inscription: "No Mandatory Vaccines". New polls by the Associated Press- NORC Center for Public Affairs Research suggest that half of Americans would decline COVID-19 vaccine [46]. According to another poll reported by The Conversation [47], 44\% of anti-vaxxers and $62 \%$ of people who are skeptical of vaccines indicated that they will decline COVID-19 vaccine. This agrees with the findings in the current study as most of our respondents were unwilling to take the COVID-19 vaccine. Even those who indicated support for vaccine trial in Nigeria were unwilling to submit themselves to the trial.

This is quite worrisome, because in reality, vaccines only work if enough people ( $\geq 80 \%$ ) in the community are vaccinated to serve as a protective barrier for other vulnerable individuals who have not been vaccinated. This is what experts call herd (communal) immunity and its effect is reflected in the dramatic decreases in the incidence of the disease, even when all susceptible individuals have not been vaccinated. As the herd immunity increases, the incidence of the disease also automatically decreases. But, when a higher proportion of the people are unwilling to get vaccinated or opt out of a vaccination program for one reason or the other, the community's collective immunity is weakened and the disease will escalate $[48,49]$.

High incidence of infectious diseases has been recorded in places where people declined or resisted vaccination [50]. For instance, the Northeast of Nigeria was severely plagued with poliovirus until recently due to public resistance and outright rejection of the polio vaccine by the people $[51,52]$. Anti-vaccine movement in Nigeria has been driven by tribal, religious and political sentiments, while protests against vaccination in most developed countries hinges on advocacy for respect for human rights and individual liberty. In Texas for instance, students are required to get a number of immunizations to attend school. But in 2003, the Legislature passed a law allowing kids to claim an exemption for "reasons of conscience, including religious belief," provided parents sign an affidavit [45].

There are three levels of vaccine interventions. The first is voluntary, which includes vaccines like the flu and HPV that are recommended but not required. The second is mandatory, for which penalties like fines or barring children from school can be applied. These include the polio, measles and hepatitis $\mathrm{A}$ and $\mathrm{B}$ vaccines that kids have to get to attend school. The last is compulsory, which is the category anti-vaxxers fear most. Such vaccinations occur when an infected person defies voluntary and mandatory interventions and continues to spread disease around the community. A judge can decide if the person should be taken into custody and forcibly vaccinated. However, there's no instance for compulsory vaccinations on a widespread level. Considering the storm that have bedeviled the COVID-19 era, experts opined that that when a COVID-19 vaccine is eventually approved, it will likely fall into the voluntary category [45].

While the state has the authority to make a prospective coronavirus vaccine mandatory or compulsory, this preposition must be exercised with ultimate caution. To make COVID-19 vaccine mandatory or compulsory with the current anti-vaccine trends in Nigeria, without adequate public awareness, will not only be considered a violation of fundamental human rights, but will also fuel the anti-vaccine movement and undermine efforts in curbing the pandemic $[50,53,54]$. A balance is therefore needed between respect for individual liberty and the need for medical interventions like vaccination to curb a deadly pandemic $[45,52]$.
Furthermore; many of our respondents indicated various fears, including fear of adverse effects and potential complications that may be associated with the vaccine trial. Many of them also reported that they suffered one side effect or the other following the last vaccination they received. This is consistent with the present realities as researchers at the Oxford University have notified the trial volunteers that some of them may get a sore arm, headaches or fevers in the first couple of days after vaccination with the adenovirus based vaccine. They were also told there is a theoretical risk that the virus could induce a serious reaction to coronavirus, which arose in some early SARS animal vaccine studies $[24,25]$. This in a way gives seemly credence to the anti-vaccine worries and fears. But despite this, experts opined that the benefits outwit the side effect at the long run.

Though researchers working on COVID-19 vaccine have a high degree of confidence (80\%) in the vaccine, but, what about the general public? How many people out there have confidence in the vaccine trial process? $32.3 \%$ of our respondents indicated that they have no confidence in the Nigeria Centre for Disease Control (NCDC) to coordinate and implement the COVID-19 vaccine trial successfully. Whether this is an issue of competence or trust, would require further studies. This situation is similar to that reported by Grantz KH, et al. [34] from the Ebola vaccine trial in Guinea, where trust was identified as a major confounding factor in the recruitment of volunteers for the trial. It appears the black race no longer have trust in the white race due to open show of racism, as well as several conspiracy theories including alleged plans to use them as experimental guinea pigs and plans to use vaccines as a medium to implant microchips to manipulate or monitor them. They are also asking questions such as why are the healthcare workers who are trying to convince them to take the vaccine, not also participating in the trials. This may explain the reason why vaccine developers are now prioritizing the recruitment of local healthcare workers into the trial as they are more likely than others to be exposed to the virus. Inclusion of healthcare workers in vaccine trial, will no doubt, stimulate the support and confidence of the public in the scientific process [24]. To this end, deliberate efforts through the global vaccine confidence project must be made to restore vaccine confidence in the populace. Sentiment for the anti-vaccine movement will continue to grow if public-health authorities failed to inspire confidence in the vaccine trial process. Individuals who are hesitant to vaccinate, should not be demonize, instead their worries and fears should be addressed. This calls for urgent public engagement and transparency. All the stake holders involve in vaccine development, evaluation and licensure, must be transparent as much as possible throughout the entire process (including disclosing potential risks and associated side effects) to inspire confidence in the public $[47,55]$.

Regarding the choice of vaccine type for clinical trial, most of our respondents indicated they would prefer a live attenuated vaccine to other types of vaccines for protection against the Coronavirus. Live attenuated vaccines are known to confer long lasting, durable and robust immunity, usually with one shot, but it is not temperature stable and requires cold chain to deliver, a major challenge in resource-limited countries like Nigeria. Besides the issue of stability, considering how deadly the new coronavirus is, it would take a longer time to alter the virus so that it becomes weak and safe enough to be used as a vaccine agent. To accelerate the process, some vaccine developers are inserting sections of the coronavirus gene into weakened, live versions of other viruses instead of using the entire coronavirus particle. The adenovirus platforms currently being used to shepherd the coronavirus gene into the body are still experimental. They have never been used for any infectious diseases. Besides, infection with adenovirus has been associated with symptoms like diarrhea and pink eye. Another concern 
is that some people may have been naturally immunized against the adenovirus due to past exposure, hence the vaccine may not work for them [56].

Furthermore, developers of DNA-based vaccines on the other hand use a viral DNA to prompt the body to create antibodies. The advantages of these types of vaccines include: adequate stimulation of both B- and T-cell responses, improved vaccine stability, the absence of any infectious agent and the relative ease of large-scale production within a short period. Being temperature-stable and cold-chain free, is an important feature for delivery to resource-limited settings [56]. However, till date, no DNA vaccine has been approved for commercial use in humans for reasons including: the risk of viral-host genome integration, the persistent of plasmids for a long time after injection (nearly 2 years) by one account [57], and the risks of oncogenic mutation amongst others. Many aspects of the immune response generated by DNA vaccines are yet to be understood. However, this has not impeded significant progress towards the use of this type of vaccine in humans, and clinical trials have begun already. Three of the eight COVID-19 candidates currently in clinical trials are either DNA or mRNA-based [4-7].

Route of administration is an integral component of the vaccine development and deployment process. A higher proportion of our respondents indicated that they would prefer the oral route for vaccine administration. This contradicts the work of Kim YC, et al. [58] who reported subcutaneous and intravenous infusion as the routes of administration for some of the ongoing vaccine trials. This may impact on the acceptance and deployment of the vaccine in Nigeria and therefore, should be considered by vaccine developers.

Experts are worried, what if we get a Covid-19 vaccine and half the country refuses to take it? Refusal to get vaccinated could put public health officials and politicians against an anti-vaccine movement that have flooded the social media with misinformation, conspiracy theories and propaganda aimed at convincing people that the vaccine is a menace rather than a lifesaving, economy-rescuing intervention $[59,60]$.

At the onset of the pandemic, wild conspiracy theories about the new coronavirus emerged online [61]. Perpetrators of the conspiracy theories have accused Bill Gates of creating the virus himself, had it patented and seeking to use Coronavirus vaccine as a gambit to monitor and control people through an injected microchip or quantum-dot spy software. The Gates conspiracy theories are part of an ocean of misinformation on COVID-19 that is spreading online. These false claims have gone viral and have resulted in several anti-coronavirus vaccine protest rallies, as well as destruction of $5 \mathrm{G}$ phone masts in different parts of the world following a conspiracy theory that linked $5 \mathrm{G}$ radiation to the coronavirus [32]. The same conspiracy theories seem to have a negative impact on the current study, as many social media users with vaccine bias decline to participate in the survey. This partly explains the poor participation seen in this study.

Over $80 \%$ of our respondents like other similar studies had the social media as their major source of information on COVID-19. The social media had been noted as a pool of both fake and right information which leaves the readers with the herculean task of choosing which to believe and which to leave out [61]. The current pandemic era has been bedevilled with misinformation (wrong information, but not deliberately misleading) and disinformation (organized falsehoods that are intended to mislead). Much of the confusion at the beginning of the pandemic has been associated with fundamental scientific uncertainties about the outbreak [61]. According to Philip B, et al. [32], escalation of inaccurate information during a pandemic, doesn't only mislead, but could be a matter of life and death if people start taking unproven drugs, ignoring public-health advice, or refuse vaccine when one becomes available [62].

The lockdown and stay at home order, afford many the liberal time and opportunities to be busy on the internet in search for answers regarding the novel coronavirus pandemic. Rumour-mongers who might once have been isolated in their local communities can connect with like-minded sceptics anywhere in the world via several socialmedia platforms, including Facebook, Reddit, WhatsApp, Instagram and Gab amongst others $[63,64]$.

Currently, about 3 billion people use the social media platform. Groups that spread vaccine misinformation on social media appear to have more impact than government health agencies and other expert organizations on undecided people $[53,65]$. They are capitalizing on both the many unknowns about the COVID-19 virus and the disease it causes, as well as the many legitimate questions about safety and efficacy as vaccines are being developed at unprecedented speed. The spread of false information could have significant public health consequences if an effective COVID-19 vaccine is developed.

There is a new world war online surrounding trust in health expertise and science, particularly with misinformation about COVID-19, but also distrust in big pharmaceuticals and governments [61]. While vaccine supporters outnumber users with anti-vaccine views on social media (Facebook), the platform has nearly three times as many antivaccination communities, according to a recent study [66]. That makes it far more likely that their views will reach people who are undecided. Anti-vaccination groups offer lots of content about vaccines and other proven health treatments-such as safety concerns, conspiracy theories or individual choice, for example. These increase their chance of influencing social media users who are undecided $[62,65,67,68]$. Scammers usually hide among the numerous (about 120,000) online domains related to the COVID-19 outbreak to mislead simple minds $[61,63,64]$. According to Philip B, et al. [32], individuals who got their information from mainstream broadcast and print media had more accurate ideas about COVID-19 than did those who got their news mostly from conservative media or from social media.

Furthermore, the fights against the pandemic have been grossly affected by both international and local politics. For instance, the China-America controversies over the origin of the virus and the Republicans- Democrats controversies over the US President's response to the pandemic, including withdrawal of funds from the World Health Organization (WHO) [2,69]. Similarly, in third world countries like Nigeria, a sizeable fight against the pandemic has been undermined by politics [70]. For instance, political opponents have been alleged to deliberately spread false news to frustrate government's effort in curbing the virus, just to score a political point. The outcome of this study reflected this assertion as $83 / 465$ (17.8\%) of our respondents believed that COVID-19 in Nigeria is a political scam with economic interest. To this end, a line of distinction must be drawn between science and politics. This is so important because health misinformation is increasingly being buried in messages that seem strictly political at first glance. This is a complicated landscape that is not just a matter of debunking a piece of misinformation. It is about relationships between the public and politicians, a lack of trust in the motives of governing powers and fears among leaders that the truth would spark public disorder and rebellion [53].

Another critical issue is that of prioritizing who gets the vaccine once it becomes available. This is very important, because there may not be enough initially to meet up with globe demand [45]. More than half of our respondents recommended that the COVID-19 vaccine be 
made available and accessible to all at no cost, regardless of religion, tribal or political affiliation. This is consistent with a poll by the Washington Post-ABC News, in which about 7 in 10 (70\%) Americans say they would get a vaccine to protect against the novel coronavirus if the vaccine is free and available to everyone [71]. If COVID-19 vaccine scales through and is proven effective against the coronavirus, there remains the tremendous challenge of producing enough to meet up with global demand. According to Hatchett R [72], the world will need many billions of doses of COVID-19 vaccine in coming years (2 doses per person). An estimated two billion doses would be needed to vaccinate workers in health care and other essential industries alone globally. While Brazil, China, and India all have huge vaccine industries, they also have among others the largest populations to cater for, and one would expect that they reserve their vaccine supplies for their own citizens first, before opening them up to others. Some countries like the US are already seeking to strike monopoly agreements with vaccine manufacturers to avoid domestic shortages. Another potential challenge is that of cost [73]. Experts opined that the expected high demand for the vaccine will make it extremely expensive and the common man especially in low-income countries may not be able to afford the vaccine as indicated by a significant proportion of our respondents. A survey by Berghea F, et al. [74], indicated that the acceptable price range for COVID-19 vaccine was between 20 and 200 EUR. Subgroup analyses revealed similar price range in all groups with the notable exception of those with high income who selected a 50 to 400 EUR interval. These results matched the existing optional vaccination schemes offered in the private health care sector: $43.2 \pm$ 32.1 EUR. Considering the impacts of COVID-19 on the global health and economy, making the COVID-19 vaccine available and accessible to all at no cost or at a subsidized cost is a non-negotiable option and this will require intensive collaboration and partnership across many global stakeholders.

\section{Conclusion}

Misinformation and disinformation strengthen vaccine skepticism and rejection. This could undermine efforts to end the coronavirus pandemic. The outcome of this study further underscores the need for adequate public health enlightenment on the role of safe and potent vaccine in curbing the COVID-19 pandemic. This will ensure adequate deployment and acceptance of the vaccine when it finally arrives. It would be a tragedy for the deadly virus to continue to escalate due to poor knowledge, negative perception and outright rejection of vaccine by the people. To this end, first, there is need for continuous tracking of false rumours about COVID-19 in hopes of curbing their spread. The social media companies must come up with effective strategies to 'flatten the curve' of false information regarding the COVID-19 vaccines. They must be deliberate and continuously step up efforts to flag or remove misinformation and to guide people to reliable sources. Also, they must take responsibilities for the nature and authenticity of information been circulated on their platforms. The sources of false information must be identified and nipped at the bud. Facts must be promoted above false information using appropriate fact-checking and regulatory mechanisms. Efforts to raise the profile of good information, and place a warning label on the bad must be intensified. Credible evidence must be available to counter any fake news that went viral. Second, more engagement and collaborations among research institutions, pharmaceutical companies and regulatory agencies is needed, hence the creation of the "Accelerating COVID-19 Therapeutic Intervention and Vaccine (ACTIV) Program". The private sector should also be fully supported in their drive towards development and production of COVID-19 vaccine. The World Health Organization and other multilateral institutions such as the World Bank, World Economic Forum, International Monetary Fund, Global Vaccine Alliance, Coalition for Epidemic Preparedness Innovation, Wellcome Trust, Bill and Mellinda Gates Foundations, African Vaccine Manufacturing Initiative and other Corporate bodies (Governmental and Non-governmental), too numerous to mention here should remain focused and unrelenting in financing and deploying vaccine for global use. They must ensure fair distribution among all countries when it becomes available. Finally, testing of vaccine safety and efficacy must follow global best practices, devoid of any form of political, religious or racial bias. The pursuit for vaccines to curb the COVID-19 pandemic is on and should not be at the expense of ethical principles such as informed consent and medical privacy. The COVID-19 vaccines must be safe and effective, and once this is proven, a comprehensive immunization campaign would be needed to achieve maximum acceptance by the general public.

\section{Limitations}

Firstly, the data presented in this study are self-reported and partly dependent on the participants' honesty and recall ability; thus, they may be subject to recall bias. Secondly, is the duration of the study. Responses for the survey were retrieved after 72 hours (3 days). A greater diversity in the socio-demographic characteristics of the study participants, especially in occupation, religion and geographical representation may have been observed if the survey was allowed much longer than we did. Thirdly, the conspiracy theories surrounding COVID-19, made some social media users decline participation in the survey, hence the number of responses received. Fourthly, only those with access to the internet were able to participate in the study. The outcome of this study might be different, if a non-web survey was conducted. Also, due to the closure of all educational institutions in Nigeria amidst the COVID-19 outbreak [75,76], the institutional health research and ethics committee was not approached. Despite these limitations, our findings provide valuable information about the knowledge, perceptions and readiness of Nigerians to participate the COVID-19 Vaccine Trial.

\section{Recommendations}

Our recommendations are as follow:

1. Future researchers conducting similar survey should extend the duration of the survey longer than we did to receive more responses (larger sample size) that will give a clearer picture of the knowledge, perception and readiness of Nigerians to accept the COVID-19, with respect to the socio-demographic characteristics. A correlation analysis between various criteria is highly commended.

2. They should also consider using a non-web-based approach in their survey in order to accommodate participants without access to internet.

3. Further study should be undertaken to explore the potential relationship between the various socio-demographic characteristics of the study participants and their willingness to participate in the COVID-19 vaccine trial.

4. Using the polio vaccine as a reference point, the southerners were more receptive to vaccine and vaccination, than the northerners. Therefore, we would recommend that potential vaccine investigators should consider conducting COVID-19 vaccine trial first in the southern parts of the country, before extending it to other parts of the country.

5. An aggressive campaign at the grass root to debunk the conspiracy theories surrounding COVID-19 is needed to ensure acceptance and deployment of the vaccine when it becomes available. 
6. The Federal Government of Nigeria should be more intentional in committing more resources (funds, manpower etc) to public health awareness programs to enlighten the masses about the benefits of receiving safe and effective COVID-19 vaccines, even before one becomes available.

\section{Acknowledgments}

The researchers thank all the respondents who participated in the web-based survey.

\section{Funding}

This research did not receive any funding from any agency in the public, commercial, or not-for-profit sectors.

\section{Competing Interests}

The authors declared that no competing interests exist.

\section{References}

1. Johns Hopkins University Center for Systems Science and Engineering (JHU-CSSE) (2020) Coronavirus: COVID-19 Global Cases by the JHUCSSE as at June 10, 2020.

2. Enitan SS, Ibeh IN, Oluremi AS, Olayanju AO, Itodo GE (2020) The 2019 Novel Coronavirus Outbreak: Current Crises, Controversies and Global Strategies to Prevent a Pandemic. Int J Pathog Res: 1-16.

3. Yao H, Lu X, Chen Q, Xu K, Chen Y, et al. (2020) Patient-derived mutations impact pathogenicity of SARS-CoV-2.

4. Felter C (2020) What is the world doing to create COVID-19 vaccine? Council on Foreign Relations.

5. Graham BS (2020) Rapid COVID-19 vaccine development. Sci 368: 945-946.

6. Calina D, Docea AO, Petrakis D, Egorov AM, Ishmukhametov AA, et al. (2020) Towards Effective Covid-19 Vaccines: Updates, Perspectives and Challenges (Review). Inter J Mol Med 46: 3-16.

7. Thanh Le T, Andreadakis Z, Kumar A, Román RG, Tollefsen S, et al. (2020) The COVID-19 Vaccine Development Landscape. Nat Rev Drug Discov 19: 305-306.

8. Ogbe H (2020) Global Vaccine Group urges COVID-19 Solidarity ahead of Summit. True News Nigeria.

9. World Health Organization (WHO) (2020) WHO Working Group Target Product Profiles for COVID-19 Vaccines.

10. Itodo GE, Enitan SS, Oyekale AO, Agunsoye CJ, Asukwo UF, et al. (2020) COVID-19 among Healthcare Workers: Risk of Exposure, Impacts and Biosafety Measures- A Review. Int J Health Safety Environ 6: 534-548.

11. Nunneley C (2020) COVID-19 vaccine candidates: 6 front-runners. $A B C$ News.

12. Begum J, Akbar-Mir N, Dev K, Buyamayum B, Wani MY, et al. (2020) Challenges and prospects of COVID-19 vaccine development based on the progress made in SARS and MERS vaccine development.

13. Singh K, Mehta $S$ (2016) The clinical development process for a novel preventive vaccine: An overview. J Postgrad Med 62: 4-11.

14. World Health Organization (2020) Criteria for COVID-19 vaccine prioritization.

15. World Health Organization (2020) WHO Working Group Core Protocol for vaccines against COVID-19.

16. European Vaccine Initiative (2020) Today's catalyst for tomorrows Vaccines. London.
17. Global Alliance for Vaccines and Immunization (GAVI) News Letter (2020) The latest in the COVID-19 vaccine race.

18. Ahmed SF, Quadeer AA, McKay MR (2020) Preliminary Identification of Potential Vaccine Targets for the COVID-19 Coronavirus (SARSCoV-2) Based on SARS-CoV Immunological Studies. Viruses 12: 1-15.

19. Ozkan K (2020) How Close are We to a COVID-19 Vaccine? J Pure Applied Microbiol 14: 893-902.

20. Patel SK, Pathak M, Tiwari R, Yatoo MI, Malik YS, et al. (2020) A vaccine is not too far for COVID-19. J Infect Dev Countries 14: 450453.

21. World Health Organization (2020) Overview of the types/classes of candidate vaccines against SARS-CoV-2.

22. World Health Organization (2020) An international randomized trial of candidate vaccines against COVID-19.

23. National Institutes of Health (NIH) (2020) NIH clinical trial of investigational vaccine for COVID-19 begins.

24. Walsh $F(2020)$ Coronavirus: First patients injected in UK vaccine trial. BBC News.

25. Indian Times (2020) COVID-19 vaccine trial: Oxford University to recruit 500 volunteers.

26. Igomu T (2020) COVID-19: Nigeria to join solidarity drug trials-WHO. Punch-Healthwise.

27. Sahara Reporters (2020) WHO to commence clinical trial of COVID-19 Vaccines in Nigeria. New York.

28. Nigeria Centre for Disease Control (NCDC) (2020) COVID-19 Situation Report 104

29. Odutola A (2020) Covid-19: CBN wants to fund research for Nigerian Made vaccines. Nairametrics.

30. Ajayi O (2020) Nigeria: COVID-19 -Government okays 5 States, FCT for WHO's Clinical Trials. All Africa Stories.

31. Lin C (2020) An alarming number of Americans say they will not get a COVID-19 vaccine when it becomes available. Fast Company.

32. Philip B, Amy M (2020) The epic battle against Coronavirus misinformation and conspiracy theories. Nature 581: 371-374.

33. Ilesanmi O, Alele FO (2016) Knowledge, Attitude and Perception of Ebola Virus Disease among Secondary School Students in Ondo State, Nigeria, October, 2014. PLoS Curr 8.

34. Grantz KH, Claudot $P$, Kambala $M$, Kouyaté $M$, Soumah $A$, et al. (2019) Factors influencing participation in an Ebola vaccine trial among front-line workers in Guinea. Vaccine 37: 7165-7170.

35. World Health Organization (2020) Emergencies preparedness, response: Disease Outbreak News in Nigeria.

36. World Medical Association (WMA) (2013) WMA Declaration of Helsinki-Ethical Principles for Medical Research Involving Human Subjects. $64^{\text {th }}$ WMA General Assembly, Fortaleza, Brazil.

37. Shott $S$ (1990) Statistics for health professionals. $7^{\text {th }}$ (eds). WB Saunders Co. The University of Michigan: 418, USA.

38. Powell JH, Fleming Y, Walker-McGill CL, Lenoir M (2008) The project IMPACT experience to date: increasing minority participation and awareness of clinical trials. J Natl Med Assoc 100: 178-187.

39. Detoc M, Launay O, Dualé C, Mutter C, Le Huec JC, et al. (2019) Barriers and motivations for participation in preventive vaccine clinical trials: Experience of 5 clinical research sites. Vaccine 37: 6633-6639. 
40. Olapegba PO, Ayandele O (2020) Survey data of COVID-19-related Knowledge, Risk Perceptions and Precautionary Behavior among Nigerians. Data in Brief 30: 105685.

41. Akshaya SB, Wafa AA, Jamal R, Mohammadjavad AM, Deepak KB (2020) Novel Coronavirus (COVID-19) Knowledge and Perceptions: A Survey of Healthcare Workers. medRxiv.

42. Taghrir MH, Borazjani R, Shiraly R (2020) COVID-19 and Iranian Medical Students; A Survey on Their Related-Knowledge, Preventive Behaviors and Risk Perception. Arch Iran Med 23: 249-254.

43. Saqlain M, Ahmed A, Gulzar A, Naz S, Munir MM, et al. (2020) Public's Knowledge and Practices regarding COVID-19: A crosssectional survey from Pakistan. medRxiv.

44. Perry D (2020) Millions of Americans will refuse to get a coronavirus vaccine when it becomes available, polls say. The Seattle Times.

45. Martin B (2020) Texas anti-vaxxers fear mandatory COVID-19 vaccines more than the virus itself Texas Monthly, USA.

46. Chodosh S (2020) Why only half of Americans say they would get a COVID-19 vaccine.

47. The Conversation (2020) A majority of vaccine skeptics plan to refuse a COVID-19 vaccine, a study suggests, and that could be a big problem.

48. Global Alliance for Vaccines and Immunization (GAVI) News Letter (2020) What is herd Immunity?

49. Regalado A (2020) What is herd immunity and can it stop the coronavirus? MIT Technol Rev.

50. BBC News (2019) How anti-vaccine movements threaten global health.

51. Jegede AS (2007) What led to the Nigerian boycott of the polio vaccination campaign? PLoS Med 4: e73.

52. Mgbolu C (2019) Polio in Nigeria: 'I opposed vaccinations until my son caught polio.' BBC News.

53. Heidi JL (2020) Blocking Information on COVID-19 Can Fuel the Spread of Misinformation. Nature 580: 306.

54. International Fact-Checking Network (IFCN) (2020) Covid-19 Misinformation-Poynter.

55. (2020) Coronavirus misinformation needs researchers to respond. Nature 581: 355-356.

56. Wetsman $N$ (2020) Unproven strategies lead the race for a COVID-19 vaccine. The Verge.

57. Armengol G, Ruiz LM, Orduz S (2004) The Injection of Plasmid DNA in Mouse Muscle Results in Lifelong Persistence of DNA, Gene Expression, and Humoral Response. Mol biotechnol 27: 109-118.

58. Kim YC, Dema B, Reyes-Sandoval A (2020) COVID-19 Vaccines: Breaking Record Times to First-In-Human Trials. NPJ Vaccines 5: 34.
59. Health 24 News (2020) The damage of vaccine misinformation.

60. Kevin R (2020) Get Ready for a Vaccine Information War. New York USA.

61. Jamieson $\mathrm{KH}$, Albarracín D (2020) The relation between media consumption and misinformation at the outset of the SARS-CoV-2 pandemic in the US. Harvard Kennedy Sch Misinform Rev.

62. Health 24 News (2020) Why anti-vaxxers often win out on Facebook.

63. Velásquez N, Leahy R, Restrepo JN, Lupu Y, Sear R, et al. (2020) Hate multiverse spreads malicious COVID-19 content online beyond individual platform control. ArXiv.

64. Donovan J (2020) Social-media companies must flatten the curve of misinformation. Nature.

65. Chen E, Lerman K, Ferrara E (2020) Tracking Social Media Discourse About the COVID-19 Pandemic: Development of a Public Coronavirus Twitter Data Set. JMIR Public Health and Surveil 6: e19273.

66. Cinelli M, Quattrociocchi W, Galeazzi A, Valensise CM, Brugnoli E, et al. (2020) The covid-19 social media infodemic. arXiv.

67. Johnson NF, Velásquez N, Restrepo NJ, Leahy R, Gabriel N, et al. (2020) The Online Competition Between Pro- And Anti-Vaccination Views. Nature 582: 230-233.

68. Preidt R (2020) Why Anti-Vaxxers often win out on Facebook. US News.

69. Marcus J (2020) Coronavirus: US-China battle behind the scenes. BBC News.

70. Donnelly E, Hassan I (2020) Nigeria's Political Leaders Need to Win Trust to Tackle COVID-19. Chatham House.

71. Goldstein A, Clement S (2020) 7 in 10 Americans would be likely to get a coronavirus vaccine, Post-ABC poll finds. The Washington Post.

72. Hatchett R (2020) Manufacturing of COVID-19 Vaccines: An oral presentation by the CEO, Coalition for Epidemic Preparedness Innovation at the Africa's Leadership Role in COVID-19 Vaccine Development and Access: A Virtual Conference organized by the Africa Centre for Disease Control and Prevention in Collaboration with the African Union, Africa CDC.

73. Health Opera News (2020) After Calling Him the Antichrist, Nigerians Will Apologize to Bill Gates When this Happens.

74. Berghea F, Berghea CE, Abobului M, Vlad VM (2020) Willingness to Pay for a for a Potential Vaccine Against SARS-CoV-2/COVID-19 Among Adult Persons. Res Square.

75. Adedigba A (2020) Coronavirus: Nigerian Government orders closure of schools nationwide. Premium Times.

76. Jimoh A (2020) Why we can't reopen schools now-FG. Daily Trust. 